Supporting Information

\title{
In situ Growth of Free-standing All Metal Oxide
}

\section{Asymmetric Supercapacitor}

Bo-Si Yin ${ }^{1}$, Zhen-Bo Wang ${ }^{1, *}$, Si-Wen Zhang ${ }^{1}$, Chang Liu ${ }^{1}$, Qing-Qing Ren, ${ }^{1} \mathrm{Ke} \mathrm{Ke}^{1 *}$

${ }^{1}$ MIIT Key Laboratory of Critical Materials Technology for New Energy Conversion and

Storage, School of Chemistry and Chemical Engineering, Harbin Institute of Technology, No.92 West-Da Zhi Street, Harbin, 150001 China.

E-mail: wangzhb@hit.edu.cn; Tel.: +86-451-86417853; Fax: +86-451-86418616 


\section{Experimental Section}

All reagents in the experiments are of analytical grade and used without further purification. All the solutions were prepared in deionized water. The button type alkaline aqueous ASC device was assembled by the following procedures.

\subsection{Preparation of $\mathrm{SnO}_{2}$ nanosheets}

Prior to the synthesis, a piece of $\mathrm{CC}\left(1 \times 1 \mathrm{~cm}^{2}\right)$ was cleaned with acetone, ethanol, and distilled water in sequence. In a typical synthesis, $0.56 \mathrm{~g}$ of $\mathrm{SnCl}_{2} \cdot 2 \mathrm{H}_{2} \mathrm{O}$ and $1.47 \mathrm{~g}$ of $\mathrm{Na}_{3} \mathrm{C}_{6} \mathrm{H}_{5} \mathrm{O}_{7} \cdot 2 \mathrm{H}_{2} \mathrm{O}$ were dissolved in $40 \mathrm{~mL}$ of an ethanol-water $(1: 1)$ solution at room temperature. After stirring for $60 \mathrm{~min}$, the homogeneous solution was transferred into a $50 \mathrm{~mL}$ autoclave and the cleaned carbon cloth was immersed into the solution. Then, the autoclave was sealed and heated at $180{ }^{\circ} \mathrm{C}$ for $8 \mathrm{~h}$ in an electric oven. When the autoclave was cooled to room temperature, the $\mathrm{CC}$ coated with precursor was taken out and washed with deionized water. Finally, the precursor on $\mathrm{CC}$ was annealed at $350{ }^{\circ} \mathrm{C}$ for $2 \mathrm{~h}$ in air.

\subsection{Preparation of $\mathrm{SnO}_{2} / \mathrm{MnO}_{2}$ hierarchical nanosheets network}

The uniform growth of $\mathrm{MnO}_{2}$ nanoflakes on the surface of $\mathrm{SnO}_{2}$ nanosheets was conducted by placing the above carbon cloth in the Teflon-lined autoclave containing a certain amount of $\mathrm{KMnO}_{4}$ solution, maintained at $180{ }^{\circ} \mathrm{C}$ for $1 \mathrm{~h}$. After cooling to room temperature, the $\mathrm{CC}$ was picked out, washed with deionized water, and dried at $60{ }^{\circ} \mathrm{C}$ to obtain the $\mathrm{SnO}_{2} / \mathrm{MnO}_{2}$ hierarchical nanosheets network.

\subsection{Synthesis of 3D NiO open porous nanoribbons network}

The 3D NiO open porous nanoribbons network was grown on the nickel foam substrate by a simple solvothermal route in a Teflon-lined autoclave at $180{ }^{\circ} \mathrm{C}$ for $15 \mathrm{~h}$, using only nickel nitrate hydrate $\mathrm{Ni}\left(\mathrm{NO}_{3}\right)_{2} \cdot 6 \mathrm{H}_{2} \mathrm{O},(0.872 \mathrm{~g})$ as the nickel source, ethanol-water $(1: 1)$ as the mixed solvent without any additive. ${ }^{1-5}$ The nickel foam was annealed at $350{ }^{\circ} \mathrm{C}$ for $2 \mathrm{~h}$ in air 
washed with distilled water and absolute ethanol, and finally dried at $60{ }^{\circ} \mathrm{C}$ for $6 \mathrm{~h}$ before characterization.

\subsection{Fabrication of the ASC device}

The BSC hybrid device was constructed with $\mathrm{SnO}_{2} / \mathrm{MnO}_{2}$ negative electrode and $\mathrm{NiO}$ positive electrode separated with a porous polypropylene-based membrane (Celgard) using 6

mol L ${ }^{-1} \mathrm{KOH}$ aqueous solution as electrolyte, then assembled into CR2025 coin cells. For comparison, PVA-KOH $\left(6 \mathrm{~mol} \mathrm{~L}^{-1}\right)$ gel electrolyte is also been prepared.

\section{Characterization of materials}

The crystalline structures of the as-obtained products were characterized using X-ray diffractometer (XRD, Rigaku Dmax-2600/pc, $\mathrm{Cu}$ K $\alpha$ radiation, $\lambda=0.1542$ nm, $40 \mathrm{KV}, 150$ $\mathrm{mA}$ ). The detailed morphologies of the samples were characterized by scanning electron microscope (SEM, Hitachi-SU-70) and energy dispersive spectroscopy (EDS), attached with SEM, respectively. X-ray photoelectron spectroscopy (XPS) was carried out by using the Physical Electronics PHI model 5700 instrument and a field emission transmission electron microscopy (FETEM) (JEM-2100). The specific surface area of the as-prepared material was estimated using the Brunauer-Emmett-Teller (BET) equation based on the nitrogen adsorption isotherm obtained with a Belsorp-max. The pore size distribution was determined with the Barrett-Joyner-Halenda (BJH) method applied to the desorption branch of adsorptiondesorption isotherm.

\section{Electrochemical performance measurements}

\subsection{Three-electrode system}

The electrochemical performances of $\mathrm{CC} / \mathrm{SnO}_{2} / \mathrm{MnO}_{2}$ composite and $\mathrm{NiO} / \mathrm{Ni}$ foam were detected by cyclic voltammetry (CV), galvanostatic charge-discharge and electrochemical 
impedance spectroscopy (EIS) in a three-electrode system in the $1 \mathrm{~mol} \mathrm{~L}^{-1} \mathrm{KOH}$ electrolyte, in which a Pt foil and a saturated calomel electrode (SCE) were used as the counter electrode and the reference electrode, respectively.

The capacitance $\left(\mathrm{C}_{\mathrm{s}}, \mathrm{F} \mathrm{\textrm {g } ^ { - 1 }}\right)$ of the pseudocapacitive electrode can be calculated in accordance with the following equation: ${ }^{6}$

$$
\mathrm{C}_{\mathrm{s}}=\int \mathrm{Id} V / v m V
$$

Where I is the response current density(A), V is the voltage change (V) excluding IR drop in the discharge process, $v$ is the scan rate and $\mathrm{m}$ is the mass of the active material $(\mathrm{g})$. The $\mathrm{CC} / \mathrm{SnO}_{2} / \mathrm{MnO}_{2}$ mass loading is about $\approx 1.5 \mathrm{mg}$. The average mass of $\mathrm{NiO}$ is $\approx 3 \mathrm{mg}$.

\subsection{ASC device}

It is necessary to maintain charge balance between positive and negative electrodes in a ASC device. That is

$$
q^{+}=q^{-} \quad \mathrm{S}(2)
$$

Where $q^{+}$and $q^{-}$are electrical charges stored in the positive and negative electrodes, respectively. The optimal mass ratio between electrochemically active species in the positive and negative electrodes should satisfy the following equation:

$$
\mathrm{R}=\frac{\mathrm{m}_{+}}{\mathrm{m}_{-}}=\frac{\mathrm{C}_{-} \Delta \mathrm{V}_{-}}{\mathrm{C}_{+} \Delta \mathrm{V}_{+}}
$$

Where $\mathrm{m}+$ and $\mathrm{m}$ - are the masses, $\mathrm{C}\left(\mathrm{F} \mathrm{g}^{-1}\right)$ is the specific capacitance of electrode and $\Delta \mathrm{V}$ is the voltage change $(\mathrm{V})$.

In the case of the ASC device, its energy density $\left(\mathrm{E}, \mathrm{Wh} \mathrm{kg}^{-1}\right)$ and power density $\left(\mathrm{P}, \mathrm{W} \mathrm{kg}^{-1}\right)$ were calculated by generally adopted equations:

$$
\mathrm{P}=\mathrm{E} / \mathrm{t} \quad \mathrm{S}(4)
$$




$$
\mathrm{E}=\mathrm{C} \Delta \mathrm{V}^{2} / 2 \quad \mathrm{~S}(5)
$$

In the above equations, $\mathrm{C}$ is the specific capacitance of the asymmetric supercapacitors calculated according to the $\mathrm{CV}$ curves based on the total weight of the electroactive materials in two electrodes, $\Delta \mathrm{V}$ is the voltage scan range and $\mathrm{t}$ is the discharge time.

\section{The growth mechanism for $\mathrm{SnO}_{2}$}

The $\mathrm{SnO}_{2}$ hierarchical structures are prepared via hydrolysis and oxidation of tin(II) ions in a basic aqueous solution. The chemical reactions taken place could be described as follows ${ }^{7}$ :

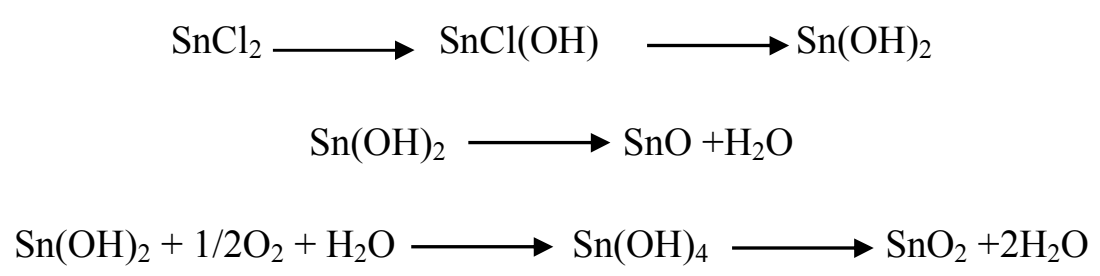

At first, a large number of tiny primary $\mathrm{SnO}_{2}$ nanocrystals were formed due to the hydrolysis of $\mathrm{SnCl}_{2}$. While in the second step, due to "oriented attachment" growth process, the grown small $\mathrm{SnO}_{2}$ nanoparticles are assembled with each other to form nanosheets. 


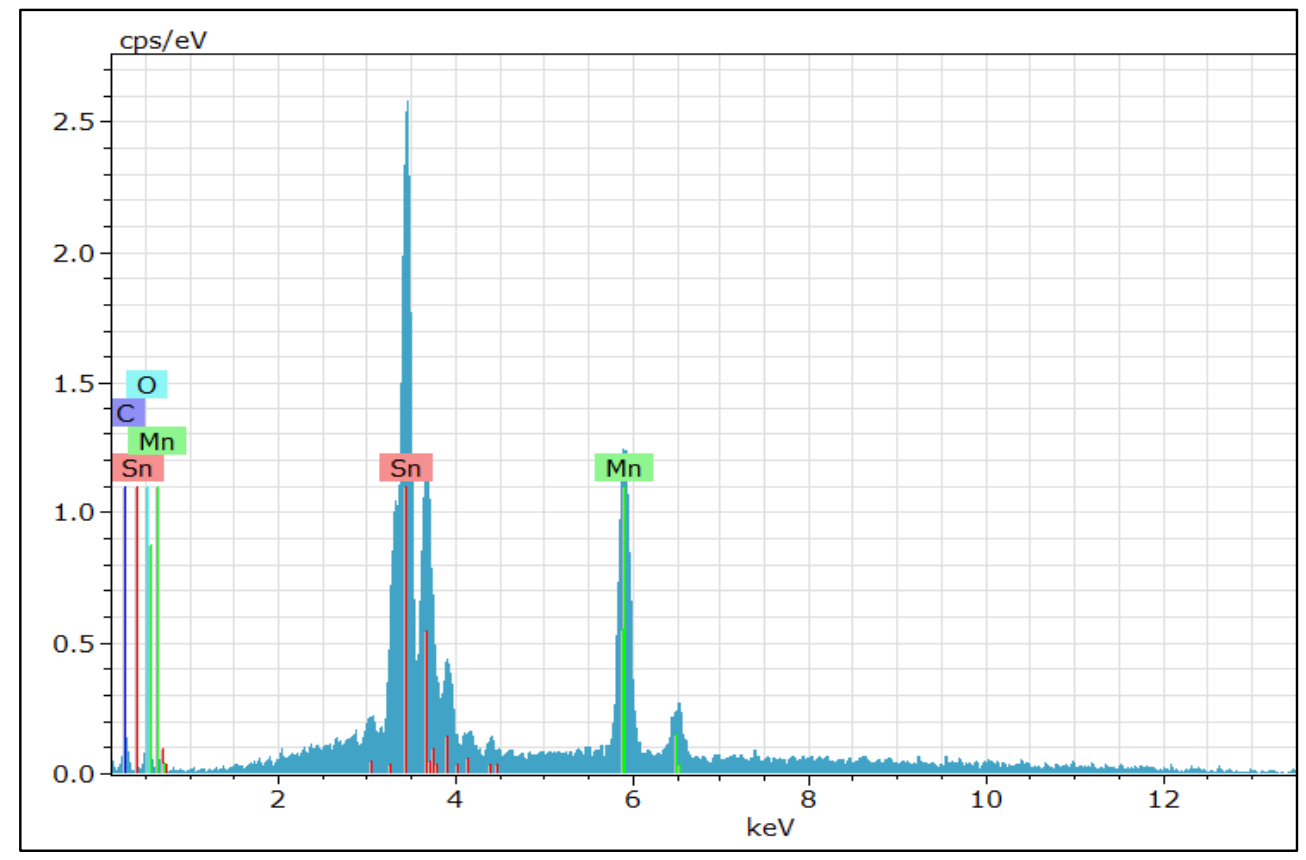

Figure S1. The corresponding EDS spectrum test of the yellow area marked in the inset of Fig. 

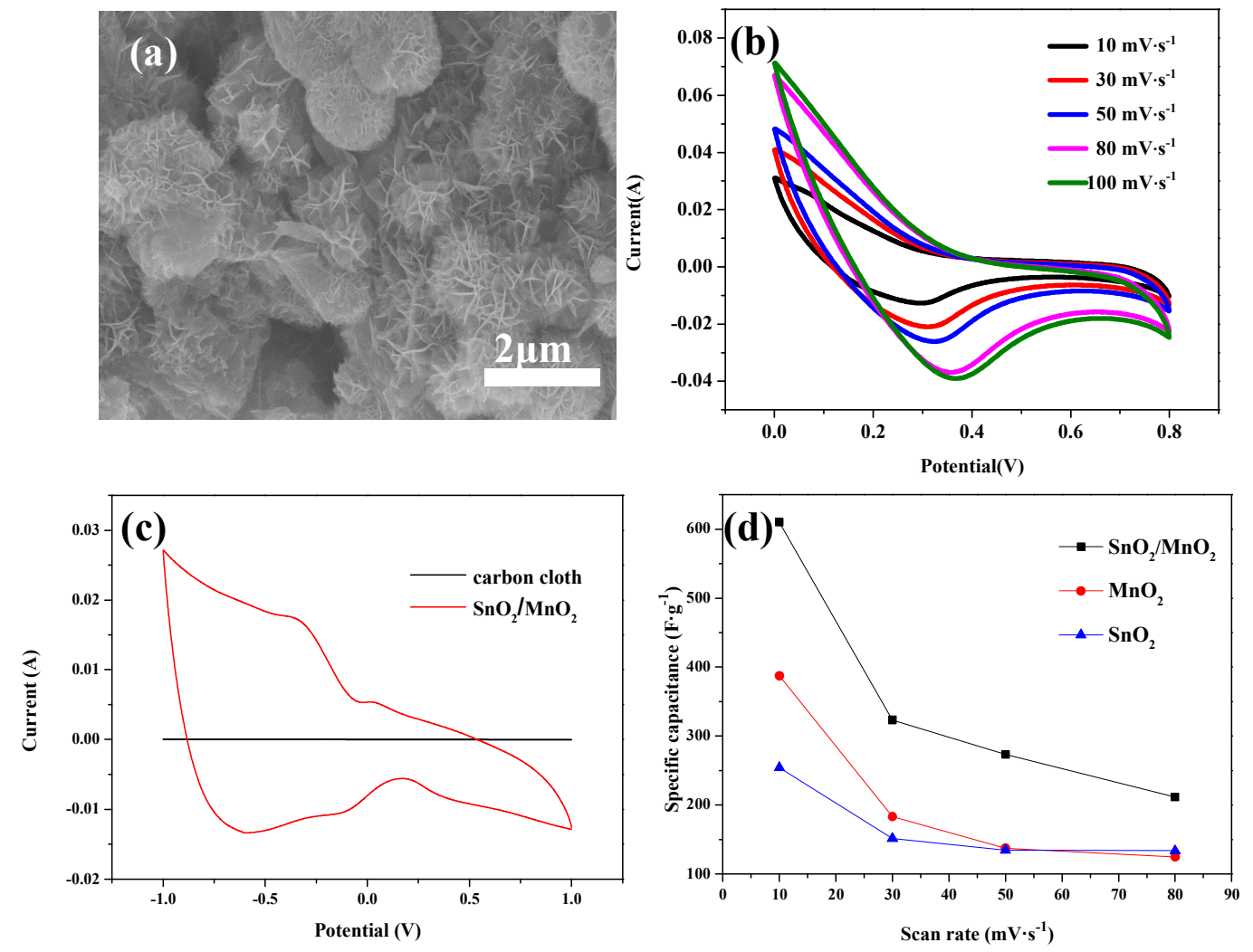

Figure S2. (a) The SEM image of the pure $\mathrm{MnO}_{2}$. (b) The cyclic voltammetry (CV) curves of pristine $\mathrm{MnO}_{2}$ electrodes at $10-100 \mathrm{mV} \mathrm{s}^{-1}$. (c) Comparative $\mathrm{CV}$ curves of carbon cloth and $\mathrm{SnO}_{2} / \mathrm{MnO}_{2}$ anode performed in a three-electrode cell at scan rate of $80 \mathrm{mV} \mathrm{s}^{-1}$. (d) The specific capacitance of $\mathrm{SnO}_{2}, \mathrm{MnO}_{2}$ and $\mathrm{SnO}_{2} / \mathrm{MnO}_{2}$. 


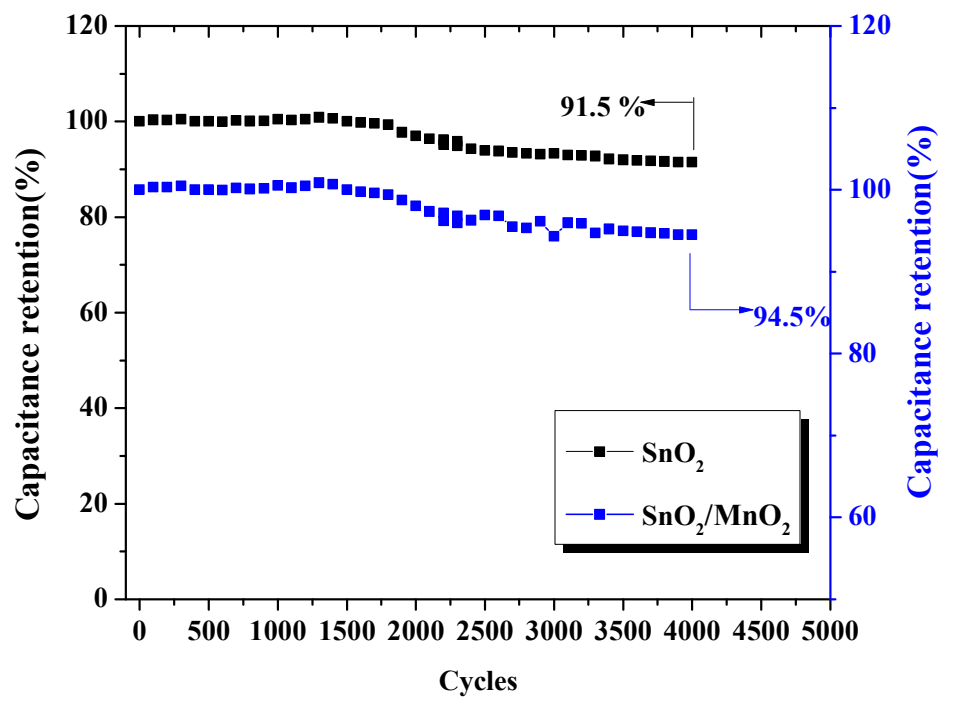

Figure S3. Cycle stability of $\mathrm{SnO}_{2}$ and $\mathrm{SnO}_{2} / \mathrm{MnO}_{2}$ investigated with a scan rate of $2 \mathrm{mV} \mathrm{s}^{-1}$ for 4000 repetitive cycles. 


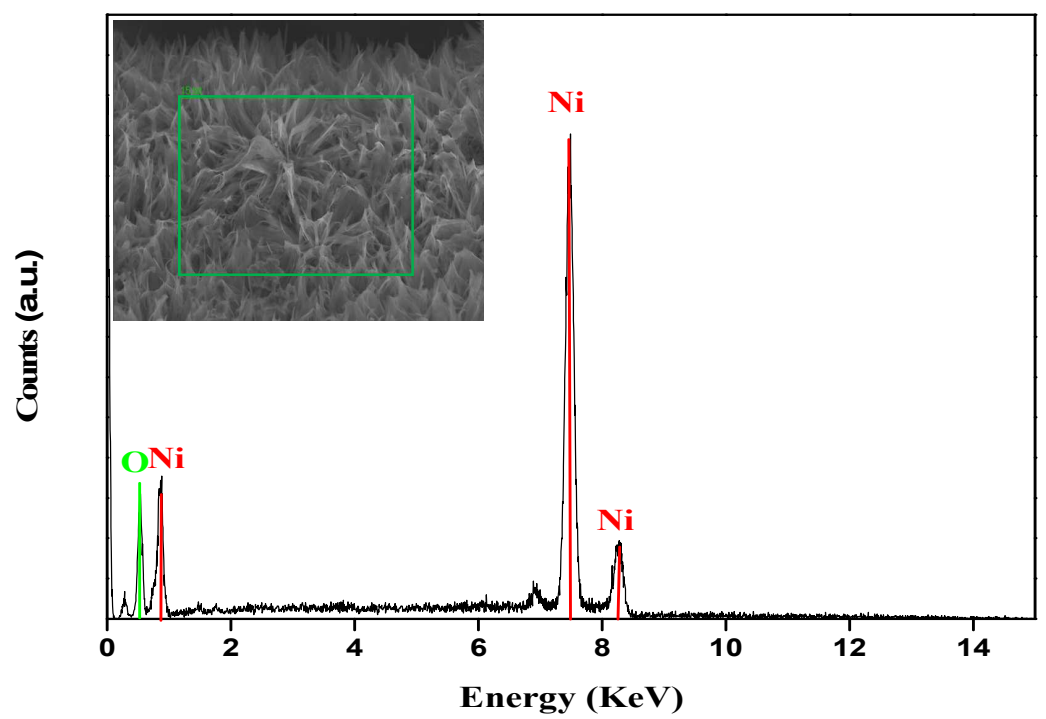

Figure S4. The EDS analysis of NiO. 

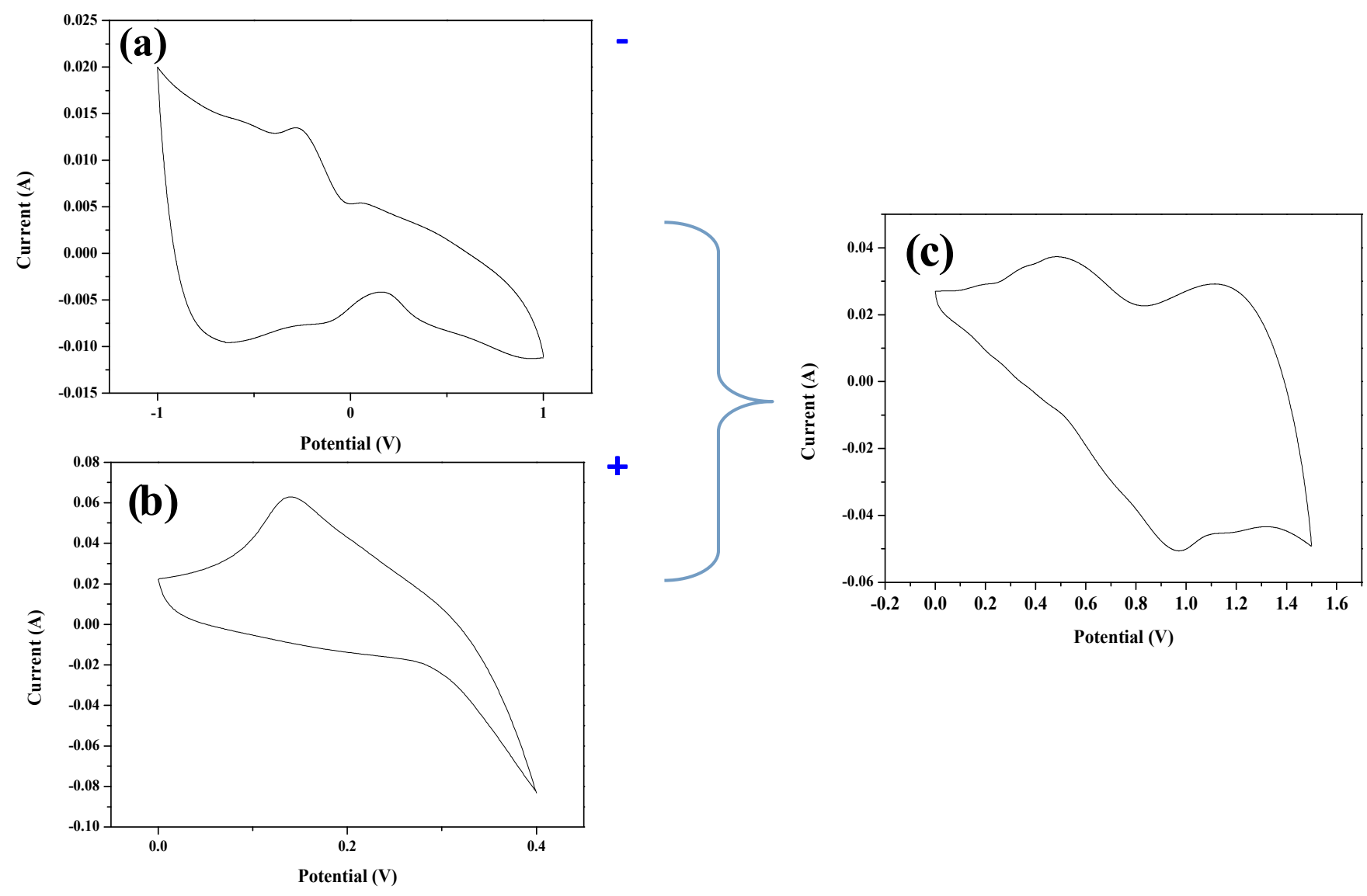

Figure S5. (a-b) Comparative $\mathrm{CV}$ curves of $\mathrm{SnO}_{2} / \mathrm{MnO}_{2}$ anode and $\mathrm{NiO}$ cathode performed in a three-electrode cell in $\mathrm{KOH}$ at scan rate of $50 \mathrm{mV} \mathrm{s}^{-1}$. (c) The $\mathrm{CV}$ curve of $\left(\mathrm{CC} / \mathrm{SnO}_{2} / \mathrm{MnO}_{2}\right)_{(-)} / /(\mathrm{NiO} / \mathrm{Ni} \text { foam })_{(+)}$supercapacitor. 

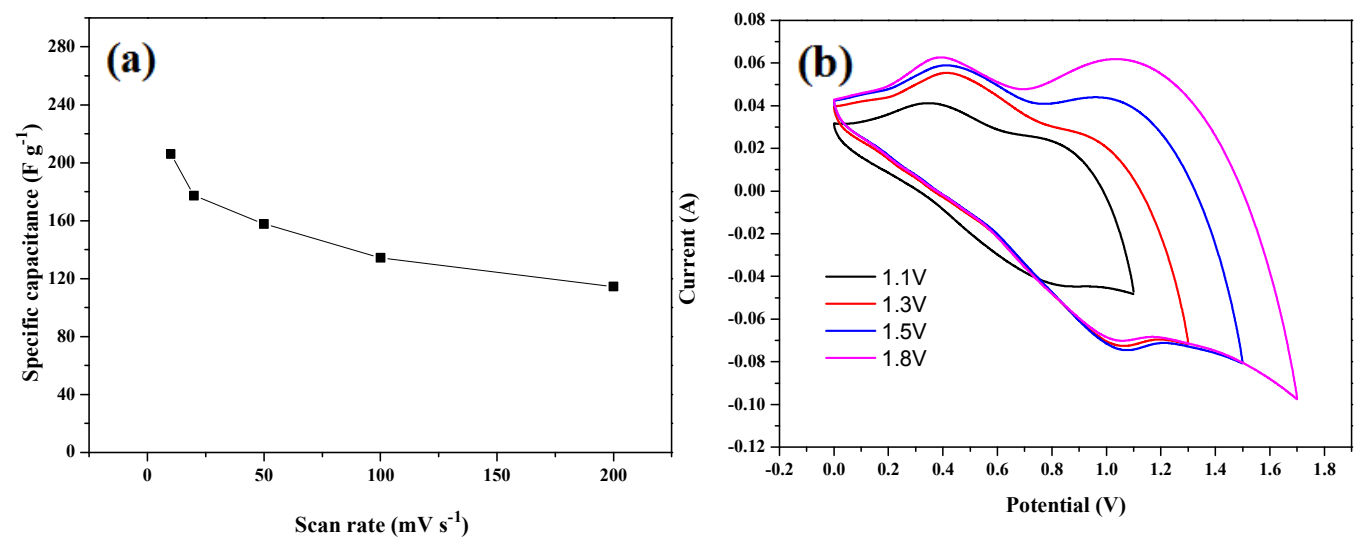

Figure S6. (a) The capacitance of the supercapacitor elucidated in the potential range of 0 to $1.5 \mathrm{~V}$ at different scan rates. (b) The $\mathrm{CV}$ curves versus different potential windows. 


\section{References}

1. Wang, L.; Hao, Y. J.; Zhao, Y.; Lai, Q. Y.; Xu, X. Y. Hydrothermal Synthesis and Electrochemical Performance of $\mathrm{NiO}$ Microspheres with Different Nanoscale BuildingBl ocks. J. Solid State Chem. 2010, 183, 2576-2581.

2. Ding, S.; Chen, J. S.; Lou, X. W. Glucose-Assisted Growth of $\mathrm{MoS}_{2}$ Nanosheets on CNT Backbone for Improved Lithium Storage Properties. Chem.-Eur. J 2011, 17, 13142.

3. Li, C. C.; Yin, X. M.; Li, Q. H.; Wang, T. H. Enhanced Gas Sensing Properties of $\mathrm{ZnO} / \mathrm{SnO}_{2}$ Hierarchical Architectures by Glucose-induced Attachment. CrystEngComm. 2011, 13, 1557-1563.

4. Pang, H.; Lu, Q.; Wang, J.; Li, Y.; Gao, F. Glucose-assisted Synthesis of Copper Micropuzzles and Their Application as Nonenzymatic Glucose Sensors. Chem. Commun. 2010, 46, 2010.

5. Qian, Y.; Liu, R.; Wang, Q. F.; Xu, J.; Chen, D.; Shen, G. Z. Efficient Synthesis of Hierarchical NiO Nanosheets for High-Performance Flexible All-Solid-State Supercapacitors. J. Mater. Chem. A 2014, 2, 10917-10922.

6. Wu, D. J.; Xu, S. H.; Li, M.; Zhang, C.; Zhu, Y. P.; Xu, Y. W.; Zhang, W. W.; Huang, R.; Qi, R. J.; Wang, L. W.; Chu, P. K. Hybrid $\mathrm{MnO}_{2} / \mathrm{C}$ Nano-composites on a Macroporous Electrically Conductive Network for Supercapacitor Electrodes. J. Mater. Chem. A 2015, 3, $16695-16707$.

7. Liu, Y.; Jiao, Y.; Zhang, Z. L.; Qu, F. Y.; Umar, A.; Wu, X. Hierarchical $\mathrm{SnO}_{2}$ Nanostructures Made of Intermingled Ultrathin Nanosheets for Environmental Remediation, Smart Gas Sensor and Supercapacitor Applications. ACS Appl. Mater. Interfaces 2014, 6, 2174-2184. 